\title{
INTERNET ASSISTED LEARNING OF BIOCHEMISTRY
}

Lima, R.M., Gomes, M.C., Xavier-Filho, J., Oliveira, A.E.A. and Fernandes, K.V.S.

Universidade Estadual do Norte Fluminense, CBB, LQFPP, Campos dos Goytacazes, R.J.

The revolution in information technology has included the INTERNET to the available resources for biochemical education. There is a great deal of biochemical information, and the amount is increasing rapidly, indeed exponentially. The aim of this work is to analyze the biochemical issues cellular respiration, photosynthesis and membrane transport available in web pages, taking into account contents quality, trustworthiness and effectiveness. Firstly $1^{\text {st }}$ secondary level students were inquired by a questionnaire on their use of INTERNET resources. More then 80 percent of them were regular users. The results confirm the already known potential of INTERNET in education. Fourteen sites were analyzed regarding to contents, presence of bibliographical, references, authorship, titles responsible and adequacy to the target public. In relation to contents, presence of conceptual errors, illustrations and other stimulatory elements were analyzed. The great majority did not mention bibliographic references and target public. Less than half divulged responsible names and/or their graduation status. Some sites contained critical conceptual errors, as the mention of, as examples: during the cell active transport process, of energy (ATP) waste (desperdício) by the cell; the yeast is a pluricellular fungal; and the oxygen is essential for anaerobic respiration. However, one of the sites, where such errors were found, was the only one to mention enzymes and regulation steps of cellular respiration. Half of the sites present identical texts and figures. None of the analyzed sites thus was considered excellent. Our data strenghthen the need for rigorous evaluation concerning of scholarly research of biochemical theme on the web.

Supported by: UENF 